Article

\title{
Exploring Aurone Derivatives as Potential Human Pancreatic Lipase Inhibitors through Molecular Docking and Molecular Dynamics Simulations
}

\author{
Phuong Thuy Viet Nguyen *, Han Ai Huynh, Dat Van Truong, Thanh-Dao Tran and \\ Cam-Van Thi Vo *iD \\ Faculty of Pharmacy, University of Medicine and Pharmacy at Ho Chi Minh City, Ho Chi Minh City 700000, \\ Vietnam; hanhuynh1995@gmail.com (H.A.H.); dattv@ump.edu.vn (D.V.T.); daott@ump.edu.vn (T.-D.T.) \\ * Correspondence: ntvphuong@ump.edu.vn (P.T.V.N.); vocamvan@ump.edu.vn (C.-V.T.V.); \\ Tel.: +84-919520708 (P.T.V.N.); +84-937248493 (C.-V.T.V.)
}

Received: 26 August 2020; Accepted: 6 October 2020; Published: 13 October 2020

\begin{abstract}
Inhibition of human pancreatic lipase, a crucial enzyme in dietary fat digestion and absorption, is a potent therapeutic approach for obesity treatment. In this study, human pancreatic lipase inhibitory activity of aurone derivatives was explored by molecular modeling approaches. The target protein was human pancreatic lipase (PDB ID: 1LPB). The 3D structures of 82 published bioactive aurone derivatives were docked successfully into the protein catalytic active site, using AutoDock Vina 1.5.7.rc1. Of them, 62 compounds interacted with the key residues of catalytic trial Ser152-Asp176-His263. The top hit compound (A14), with a docking score of $-10.6 \mathrm{kcal} \cdot \mathrm{mol}^{-1}$, was subsequently submitted to molecular dynamics simulations, using GROMACS 2018.01. Molecular dynamics simulation results showed that $\mathbf{A 1 4}$ formed a stable complex with 1LPB protein via hydrogen bonds with important residues in regulating enzyme activity (Ser152 and Phe77). Compound A14 showed high potency for further studies, such as the synthesis, in vitro and in vivo tests for pancreatic lipase inhibitory activity.
\end{abstract}

Keywords: aurone; human pancreatic lipase; human pancreatic lipase inhibitors; molecular docking; molecular dynamics simulations

\section{Introduction}

Industrialization, urbanization, and modernization have shifted our lifestyle into an inactive one. Convenient processed food with a high degree of fat and free energy sugar exists more often in our daily diets. With these changes, the global obese and overweight population have almost tripled since 1975 [1]. Obesity, a complicated and multifactorial disease, mostly arises from the imbalance between energy intake and energy consumption in the body. Obesity elevates the risk of other serious diseases, listing as diabetes [2,3], cardiovascular disorders [4,5], and certain cancers [6]. Current FDA-approved drugs for obesity treatment are orlistat, phentermine/topiramate, naltrexone/bupropion, and liraglutide $[7,8]$. Of them, orlistat is the only over-the-counter medication with the mechanism of inhibiting human pancreatic lipase (HPL) - enzyme hydrolyzing triglycerides in the digestion and absorption of dietary fat [9]. The limitations of orlistat are its adverse and inconvenient side effects, such as flatulence, steatorrhea, nephrotoxicity, kidney stones, and pancreatitis [7]. Since orlistat, there have been no new drugs getting approval with this mechanism. The inhibition of HPL to limit dietary fat digestion and absorption has thereby received much interest in anti-obesity drug discovery.

The crystal structure of HPL (PDB ID: 1LPB) was determined by X-ray diffraction. HPL is a glycoprotein consisting of the $\mathrm{N}$ region (residues from 1 to 335 ) and the $\mathrm{C}$ region (residues from 336 to 
449), associated with a colipase [10,11]. In the $\mathrm{N}$ region, the active site consists of residues from 247 to 258 with the catalytic trial Ser152-Asp176-His263 (Figure 1). The lid domain is a surface loop made by a disulfide bridge between residues Cys237 and Cys261. The $C$ region has a double-ring structure and provides the main binding surface for colipase. There are also two hair-loop coils from amino acids 76 to 85 and $\beta 9$-loop from amino acids 204 to 224 [10]. HPL structure has two states: closed state and open state. In the open state, the lid domain binds via van der Waals interaction with $\beta 5$-loop and $\beta$ 9-loop coils opening the catalytic site of the enzyme [12,13]. A C11 alkyl phosphonate (methoxy undecyl phosphonic acid (MUP)) was co-crystallized in the active site of HPL as a lipase inhibitor [12]. FDA-approved orlistat was also known as an irreversible inhibitor of pancreatic and gastric lipase by forming a covalent bond with the lipase active site in the lumen of the digestive tract $[14,15]$.

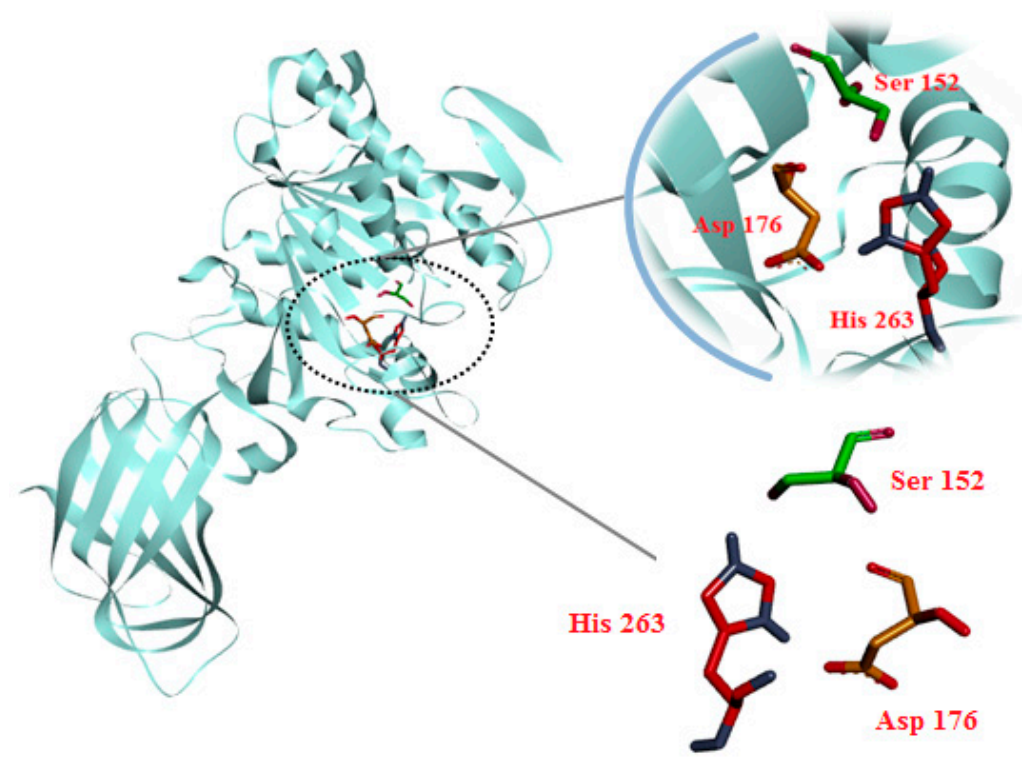

Figure 1. Three-dimensional structure of human pancreatic lipase and catalytic triad of Ser152-Asp176-His263 (PDB ID: 1LPB).

Considerable effort in recent years has been devoted to the discovery of new pancreatic lipase inhibitors. Natural plant-derived compounds (alkaloids, saponins, carotenoids, glycosides, polyphenols, polysaccharides, and terpenoids) and microorganism-derived compounds (lipstatin, valilactone, and panclicins) have been isolated and reported to inhibit in vitro and in vivo pancreatic lipase [16-18]. Synthetic compounds with diverse structures have been prepared and screened for pancreatic lipase inhibitory activity [19-22]. Along with the conventional approaches, in silico models such as 3D QSAR, 2D pharmacophore, molecular docking, and molecular dynamics simulations are utilized to identify potential bioactive compounds for obesity treatment [23-26]. Flavonoids with subclasses of flavone, flavonone, and chalcone were identified as potential candidates. $\mathrm{IC}_{50}$ values of some structures were determined, notably licochalcone A ( $\mathrm{IC}_{50} 35.00 \mu \mathrm{g} / \mathrm{mL}$ ) [27], galangin ( $\mathrm{IC}_{50} 48.20 \mathrm{mg} / \mathrm{mL}$ ) [28], hesperidin ( $\mathrm{IC}_{50} 32.00 \mu \mathrm{g} / \mathrm{mL}$ ) [29], etc. Furthermore, 36 compounds with $1 H$-inden-1,3,5,6-tetrol structure have been designed, combined with molecular docking and molecular dynamics simulations, to gain three compounds binding well to the target. These compounds were considered as potential pancreatic lipase inhibitors [25]. In a different study, four compounds, namely sanggenon $\mathrm{C}$, sanggenon D, kuwanin C, and kuwanon G, extracted from Cortex Mori Radicis, showed good HPL inhibition results with $\mathrm{IC}_{50}$ range of 0.77 to $20.56 \mu \mathrm{M}$ and $\mathrm{Ki}$ less than $5.0 \mu \mathrm{M}$. In particular, sanggenon D had the strongest inhibitory activity with $\mathrm{IC}_{50}$ of $0.77 \mu \mathrm{M}$ and $\mathrm{Ki}$ of $0.43 \mu \mathrm{M}$. Molecular docking was also performed between sanggenon D and HPL, which resulted in good binding to the active site through hydrogen interactions with Ser152 and hydrophobic interactions with Phe77 [30]. 
Aurones (2-benzylidene-1-benzofuran-3(2H)-ones) (Figure 2) belong to a minor subclass of natural flavonoids [31]. Aurones have two isomers: $(Z)$ and $(E)$. Of them, $(Z)$ isomers are experimentally more favored [32,33]. Aurones present widely in flowers and fruits. They play a crucial role in the pigmentation, typically bright yellow. They are also considered phytoalexins produced by plants in response to pathogen attack [33]. Aurone derivatives have been reported to possess different bio-activities [34], such as anti-inflammatory [35], antibacterial [36], anti-malarial [37,38], anti-hepatitis [39,40], antioxidant [41-44], anticancer [45-49], and others. However, their ability to inhibit HPL has not been studied.

In this article, we describe the exploration of aurone ability to inhibit human pancreatic lipase using molecular modeling approaches. Molecular docking on the HPL active site of the general structure of aurones, orlistat, and co-crystallized ligand was carried out as a preliminary study to determine their similarity in structures. The structures of 82 bioactive aurone derivatives were then docked into the same domain. The aurone structure with the highest docking score and proper interaction with the catalytic triad was submitted to the molecular dynamics (MD) simulations. The MD simulations of the best binding derivative and pancreatic lipase complex were performed to elucidate the dynamics behavior of the interactions between protein and ligand.

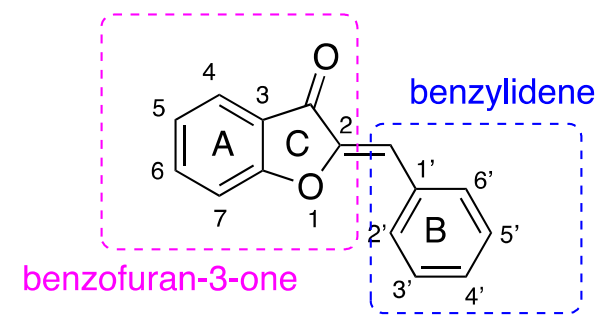

Figure 2. General structure of aurones.

\section{Results and Discussion}

\subsection{Molecular Docking}

\subsubsection{Validation of Docking Protocol}

The docking protocol was validated by redocking MUP, the co-crystallized inhibitor, into the active site of HPL. Initially, ligand MUP was retracted from the active site. It was subsequently redocked into the same domain. All conformations of MUP were located in the active site; the best conformation formed the interactions with HPL through the hydrogen bonds with Phe77, Ser152, Leu153, and His263. The resemblance of the MUP lowest binding energy pose and the experimental structure determined by X-ray crystallography proved that it was successfully mimicking the native pose. Root mean square deviation (RMSD) between the docked structure and the initial structure, using only movable heavy atoms (i.e., only ligand atoms, not hydrogen), was $0.86 \AA$ (less than $2.00 \AA$ ). Thus, docking and redocking results of MUP signified that AutoDock Vina software is reliable [50]. The protocol, therefore, can be used for docking other compounds.

\subsubsection{Comparison of the General Structure of Aurones, Orlistat, and MUP}

The general structure of aurones (A0) (Figure 2) and orlistat were docked into the same domain for comparative purpose. MUP, orlistat, and A0 had the docking scores of $-4.3,-6.7$, and $-8.8 \mathrm{kcal} \cdot \mathrm{mol}^{-1}$, respectively. Of three compounds, A0 docked best (Table 1). 
Table 1. Docking profiles of methoxy undecyl phosphonic acid (MUP), orlistat, and the general structure of aurones.

\begin{tabular}{|c|c|c|c|}
\hline Compound & $\begin{array}{c}\mathrm{DS}^{1} \\
\left(\mathrm{kcal}^{1} \mathrm{~mol}^{-1}\right)\end{array}$ & Hydrogen Bonds & Hydrophobic Interactions \\
\hline MUP & -4.3 & Ser152, Phe77, Leu153, His263 & Tyr114, Pro180, Phe215 \\
\hline Orlistat & -6.7 & Ser152, Phe77, Asp79, His151 & Phe77, Tyr114, His263 \\
\hline A0 & -8.8 & Ser152, His 263 & Phe77, Tyr114, Pro180, Phe215 \\
\hline
\end{tabular}

MUP bound to the active site with four hydrogen bonds formed by the phosphonic group of MUP with Ser152, Phe77, Leu153, and His263 of HPL. Orlistat showed strong binding to HPL with five hydrogen bonds and different hydrophobic interactions. The lactone ring and the amino acid side chain of orlistat played the key role in forming these five hydrogen bonds with residues Ser152, Phe77, His151, Asp79, and Gly76. In the case of A0, the benzofuranone ring (rings A and C) were crucial in forming two hydrogen bonds with residues Ser152 and His263. The benzofuranone ring of aurone also made the $\pi-\pi$ interactions with the aromatic rings of residues Phe77 and Phe215. The benzylidene ring (ring B) interacted with the aromatic ring of Tyr114 through the $\pi-\pi$ interaction and hydrophobic interaction with Pro180 (Figure 3). The interaction profiles of A0, orlistat, and MUP with HPL indicated their structural similarity in the enzyme active site. They all interacted with the amino acids of the catalytic trial (Ser152-Asp176-His263) and Phe77, an important amino acid for lipase activity [10,51,52]. These structural similarities hint the ability of aurones to interact with the active site of HPL.

(a)<smiles>CCCCCCCCCC[PH](=O)OC</smiles>

(b)

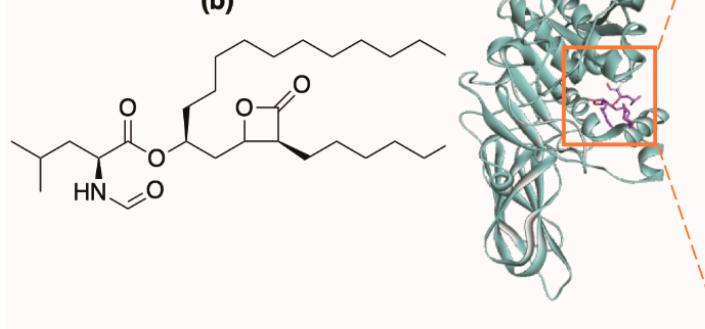

(c)

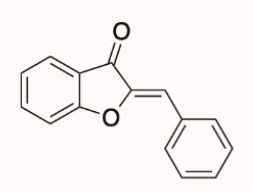

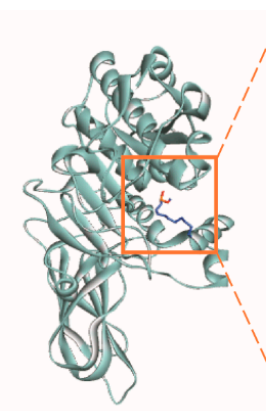
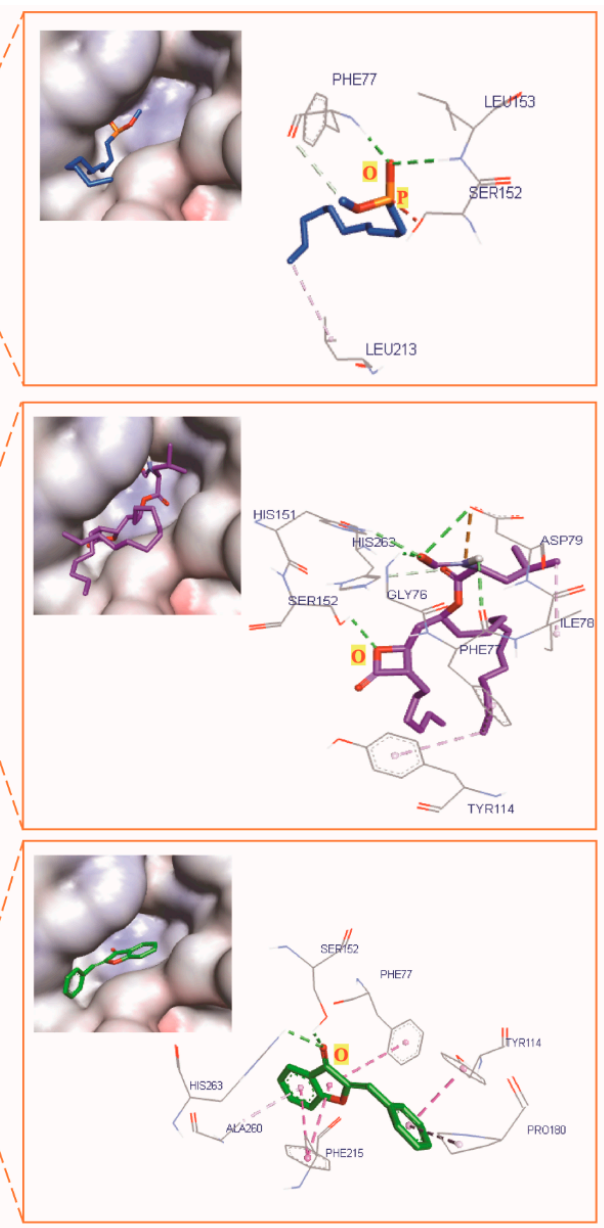

Figure 3. Docking results with protein (PDB ID: 1LPB) of (a) co-crystallized ligand MUP, (b) orlistat, and (c) general structure of aurones (A0). Lipase in blue, lipase active site residues in stick model. 


\subsubsection{Molecular Docking with Aurone Derivatives}

The 3D structures of 82 bioactive aurone derivatives collected from previous publications were docked into the active site of HPL [34-49]. Conformations of these compounds were ranked according to their binding affinities on HPL. All investigated aurone derivatives successfully bound to HPL with good docking scores, ranging from -10.6 to $-7.4 \mathrm{kcal} \cdot \mathrm{mol}^{-1}$ (Table S1). Of them, 45 compounds (55\%) had the scores less or equal to $-9.0 \mathrm{kcal} \cdot \mathrm{mol}^{-1}$, and $37 \mathrm{compounds}(45 \%)$ had the docking scores greater than $-9.0 \mathrm{kcal} \cdot \mathrm{mol}^{-1}$.

To better understand the binding mode of different aurone derivatives, we analyzed the interaction profiles of investigated compounds in addition to docking scores. Of 82 docked compounds, 62 compounds formed hydrogen bonds with the key residues of the catalyst trial Ser152-Asp176-His263 and Phe77 (Group I); 20 compounds did not have significant interactions with the key residues (Group II). For the ease of analyzing interaction profiles, Group I and Group II were further classified according to the substituent patterns of ring A (unsubstituted, monosubstituted, and disubstituted ring A) and ring B (unsubstituted, monosubstituted, and di/trisubstituted ring B) (Figure 4).

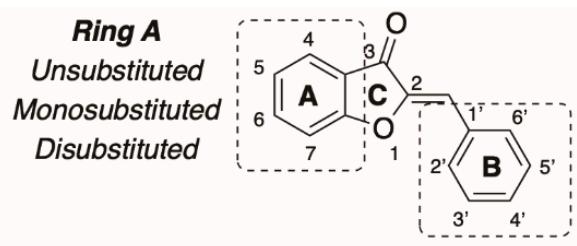

\section{Ring B}

Unsubstituted

Monosubstituted

Disubstituted

Trisubstituted

GROUP I - INTERATING WITH KEY RESIDUES

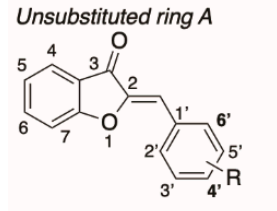

R: $\mathrm{CH}_{3}, \mathrm{OH}, \mathrm{OMe}$, halogen A1-A8

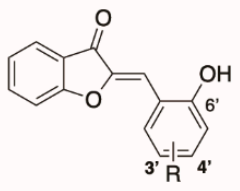

$\mathrm{R}: \mathrm{CH}_{3}, \mathrm{OMe}, \mathrm{Br}$ A9-A11

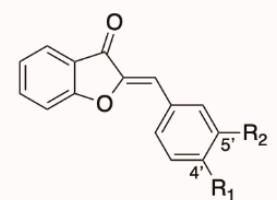

$\mathrm{R}_{1}, \mathrm{R}_{2}$ : OMe, alkyl A12, A13

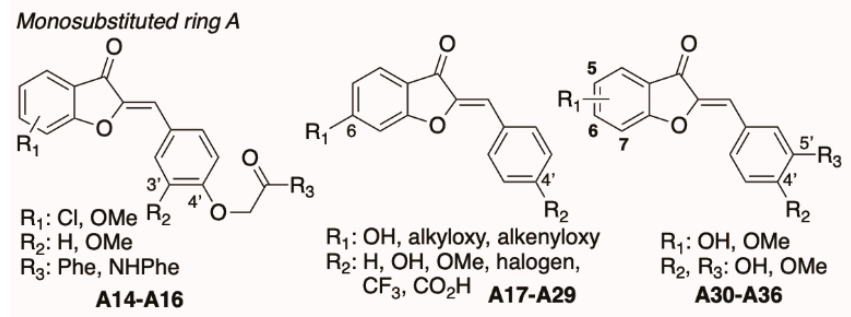

Disubstituted ring $A$
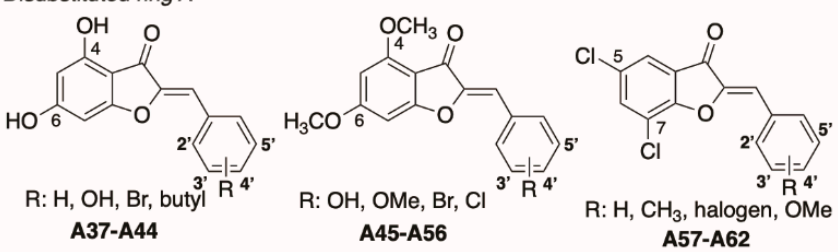

A57-A62
GROUP II - NOT INTERACTING WITH KEY RESIDUES

Unsubstituted ring A

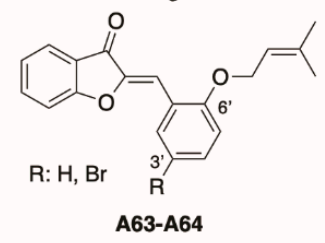

Monosubstituted ring $A$

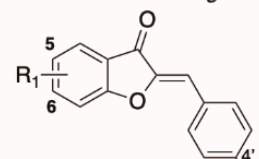

$\mathrm{R}_{1}: \mathrm{OH}, \mathrm{OCOCH}_{3}, \mathrm{Cl} N \mathrm{~N}-\mathrm{R}_{2}$ $\mathrm{R}_{2}: \mathrm{NMe}_{2}, \mathrm{NEt}_{2}$ A65-A69

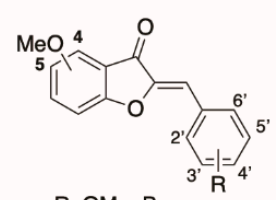

$\mathrm{R}: \mathrm{OMe}, \mathrm{Br}$

A70-A77

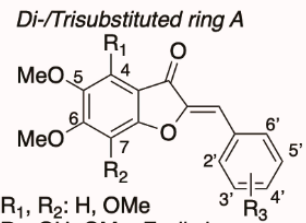

$R_{3}$ : OH, OMe, F, alkyl

A78-A82

Figure 4. Classification of 82 aurone derivatives.

Group I-Interacting with Key Residues

Unsubstituted ring A: Aurones of this group differ in substituent pattern of ring B: (1) monosubstitution with halogen, hydroxy, methoxy groups at ortho/para positions, and (2) disubstitution with hydroxy, methoxy, alkyl groups. Docking scores were in the range of -8.8 to $-10.5 \mathrm{kcal} \cdot \mathrm{mol}^{-1}$ (Table 2). 
Table 2. Docking scores of aurone derivatives in Group I and Group II.

\begin{tabular}{|c|c|c|c|c|c|}
\hline Compound & $\begin{array}{c}\text { Docking Scores } \\
\left(\mathrm{kcal} \cdot \mathrm{mol}^{-1}\right)\end{array}$ & Compound & $\begin{array}{l}\text { Docking Scores } \\
\left(\mathrm{kcal} \cdot \mathrm{mol}^{-1}\right)\end{array}$ & Compound & $\begin{array}{c}\text { Docking Scores } \\
\left(\mathrm{kcal} \cdot \mathrm{mol}^{-1}\right)\end{array}$ \\
\hline Group I & & & & Group II & \\
\hline A1-A8 & -8.8 to -10.1 & A30-A36 & -8.4 to -9.1 & A63-A64 & -9.2 to -9.4 \\
\hline A9-A13 & -8.6 to -10.5 & A37-A44 & -8.3 to -10.5 & A65-A77 & -7.4 to -10.1 \\
\hline A14-A16 & -9.9 to -10.6 & A45-A56 & -8.2 to -9.7 & A78-A82 & -8.3 to -8.8 \\
\hline A17-A29 & -8.3 to -10.2 & A57-A62 & -8.2 to -10.1 & & \\
\hline
\end{tabular}

Aurones with monosubstitution on ring B (A1-A8) were fully located in the pocket. They all have a small substituent on ring $\mathrm{B}$, including $\mathrm{OH}, \mathrm{CH}_{3}, \mathrm{OMe}$, and halogen $(\mathrm{F}, \mathrm{Cl}, \mathrm{Br})$, and were not much different from the general structure of aurones (A0). They interacted with HPL in the same fashion of A0 in which most interactions occurred at the benzofuranone ring (rings A and C) through hydrogen bonds and hydrophobic interactions with the residues Phe77, Ser152, His263, and Tyr114. Aurones with disubstitution on ring B (A9-13) docked well into the HPL active site, having the docking scores of -8.6 to $-10.5 \mathrm{kcal} \cdot \mathrm{mol}^{-1}$. Particularly, compounds with -OH group at $6^{\prime}$ position (A9-A11) interacted with HPL with the docking scores of -9.5 to $-10.5 \mathrm{kcal} \cdot \mathrm{mol}^{-1}$. Two hydrogen bonds were formed by the 3-ceton group of ring $\mathrm{C}$ and residues Ser152 and His263. The polar 6'-OH stayed in a favorable position and provided an additional hydrogen bond with Ser152. When we replaced $6^{\prime}-\mathrm{OH}$ (A11) with 6'-OMe (A6), the docking score declined. Of them, A11 had the highest docking score $\left(-10.5 \mathrm{kcal} \cdot \mathrm{mol}^{-1}\right)$ (Figure 5).

In the case that ring B consists of two adjacent substituents (A12 and A13), a part of the structure was outside the catalytic cavity, and fewer hydrogen bonds with the key residues were formed compared to A0.

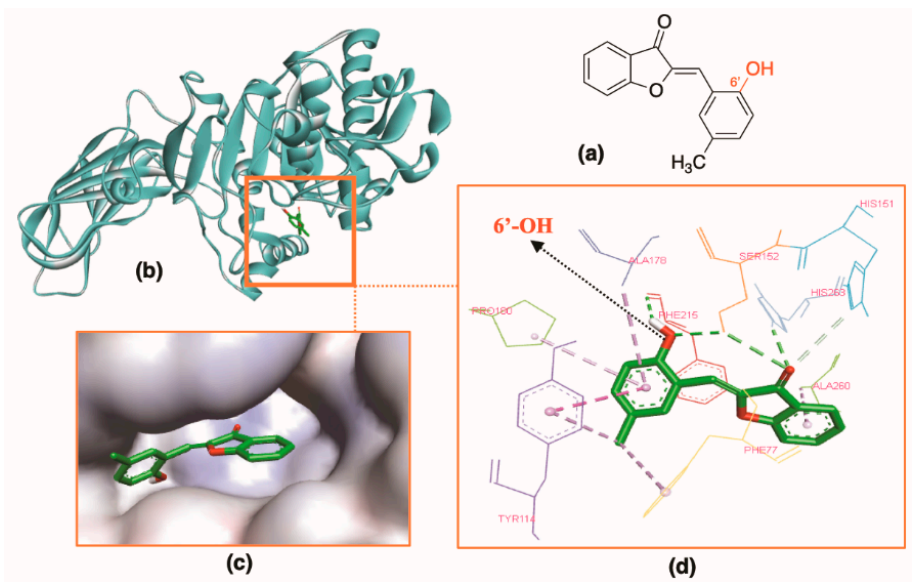

Figure 5. Docking result of A11 with protein (PDB ID: 1LPB): (a) 2D structure of A11. (b) A11 inside the active site in the ribbon style. (c) A11 in the active site surface. (d) Interactions of A11 and enzyme residues with hydrogen bonds in green and hydrophobic interactions in purple.

Monosubstituted ring A: Aurones of this group interacted with the active site in different manners. Aurones A14-A16 with ring B oxy-tethering to a functionalized aromatic ring interacted with the active site not at ring A, as in the case of general aurone structure (A0). The bulky substituent at $4^{\prime}$ position lengthens the compound size, pushing the benzofuranone ring to slide out of the catalytic cavity, away from the main residues and into the hydrophobic region. Hydrogen bonds were alternatively created by ether oxygen atom with residues Ser152 and His263. This subgroup interestingly possessed high docking scores ( -9.9 to $-10.6 \mathrm{kcal} \cdot \mathrm{mol}^{-1}$ ) (Table 2). Of which, structure A14 with Z-isomer conformation docked best into the HPL binding site $\left(-10.6 \mathrm{kcal} \cdot \mathrm{mol}^{-1}\right)$ and interacted with the key residues of the catalytic trial (Ser152 and His263) (Figure 6). 
Aurones A17-A29 with one substituent at the 6 position on ring A and one substituent at the $4^{\prime}$ position on ring B. Docking scores were -8.3 to $-10.2 \mathrm{kcal} \cdot \mathrm{mol}^{-1}$. When a substituent on ring A was small, such as $\mathrm{OH}$ and OMe (A17-A26), aurones were located fully in the active site of HPL. When substituent on ring A is larger such as ethoxy (A27), dimethylallyloxy (A28), or prenyloxy (A29), ring A slid out of the catalytic cavity, away from the key residues and in contact with the hydrophobic region.

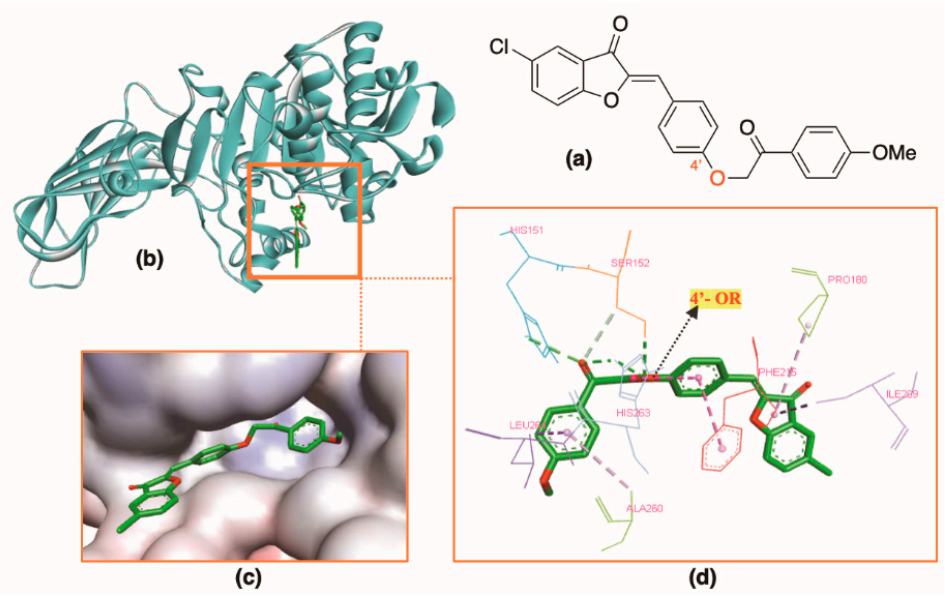

Figure 6. Docking result of A14 with protein (PDB ID: 1LPB): (a) 2D structure of A14. (b) A14 inside the active site in the ribbon style. (c) A14 in the active site. (d) Interactions of A14 and enzyme residues with hydrogen bonds in green and hydrophobic interactions in purple.

Aurones A30-A36 possessed two adjacent substituents ( $\mathrm{OH}$ and $\mathrm{OMe})$. Similar to aurones with unsubstituted ring $\mathrm{A}$ and two adjacently disubstituted ring B, a part of aurones was outside the catalytic cavity, and fewer hydrogen bonds with the key residues were observed. The docking scores of these compounds were -8.4 to $-9.1 \mathrm{kcal} \cdot \mathrm{mol}^{-1}$.

Disubstituted ring A: 4,6-Disubstituted benzofuranone aurones ( $\mathrm{OH}$ and $\mathrm{OMe})$ had a good shape and fit well in the active site. Compounds with 4,6-dihydroxy substituents (A37-A44) formed two hydrogen bonds with Phe77 and Ser152 by the $\mathrm{C}=\mathrm{O}$ group of ring $\mathrm{C}$ and one hydrophobic interaction with His263. An intramolecular hydrogen bond was formed between $4-\mathrm{OH}$ and $3-\mathrm{C}=\mathrm{O}$. This interaction might help 4,6-dihydroxy aurones in better shape for binding into HPL. When 4,6-dihydroxy groups (A37) changed to 4,6-dimethoxy groups (A45), the docking scores decreased. In this group, compound A42 (-10.5 kcal $\left.\cdot \mathrm{mol}^{-1}\right)$ was the structure binding best to the HPL (Figure 7).

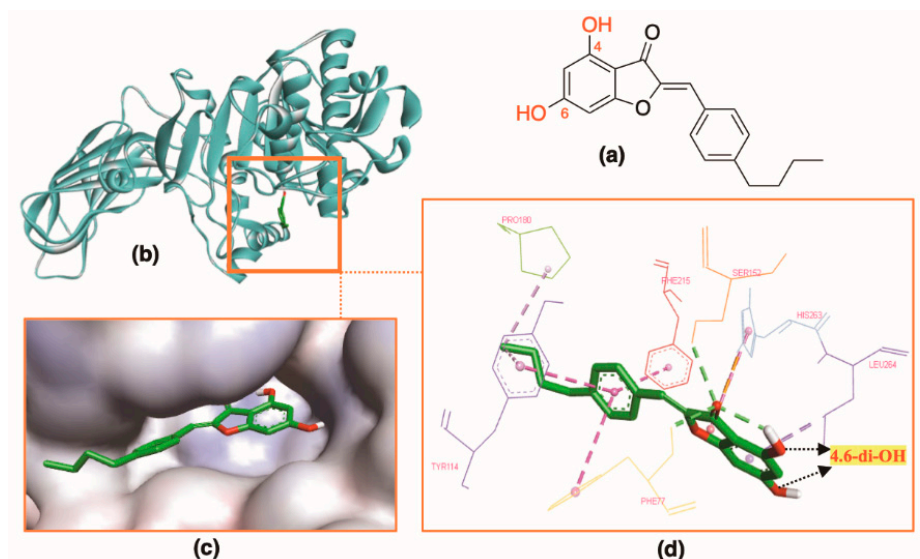

Figure 7. Docking result of A42 with protein (PDB ID: 1LPB): (a) 2D structure of A42. (b) A42 inside the active site in the ribbon style. (c) A42 in the active site surface. (d) Interactions of A42 and enzyme residues with hydrogen bonds in green and hydrophobic interactions in purple. 
Aurones with 5,7-dichlorobenzofuranone (A57-A62) interacted with Ser152 and His263 by hydrogen bonds and with Leu264, Arg256, and Ala259 through the hydrophobic interactions. Docking scores varied from -8.2 to $-10.1 \mathrm{kcal} \cdot \mathrm{mol}^{-1}$.

Group II-Not Interacting with Key Residues

Docking scores of the remaining 20 aurone derivatives were in a medium-to-good range $(-7.4$ to $-10.1 \mathrm{kcal} \cdot \mathrm{mol}^{-1}$ ) (Table 2). These compounds, however, did not interact with the key residues of the active site (Figure 8). Compounds of Group II had many adjacent methoxy substituents or branched substituents in common. These adjacent groups made the compounds bulkier; therefore, they made it difficult to penetrate the catalytic pocket. There were mostly hydrophobic interactions formed with the key residues regulating enzyme activity (Ser152, His163, Asp176, and Phe77).

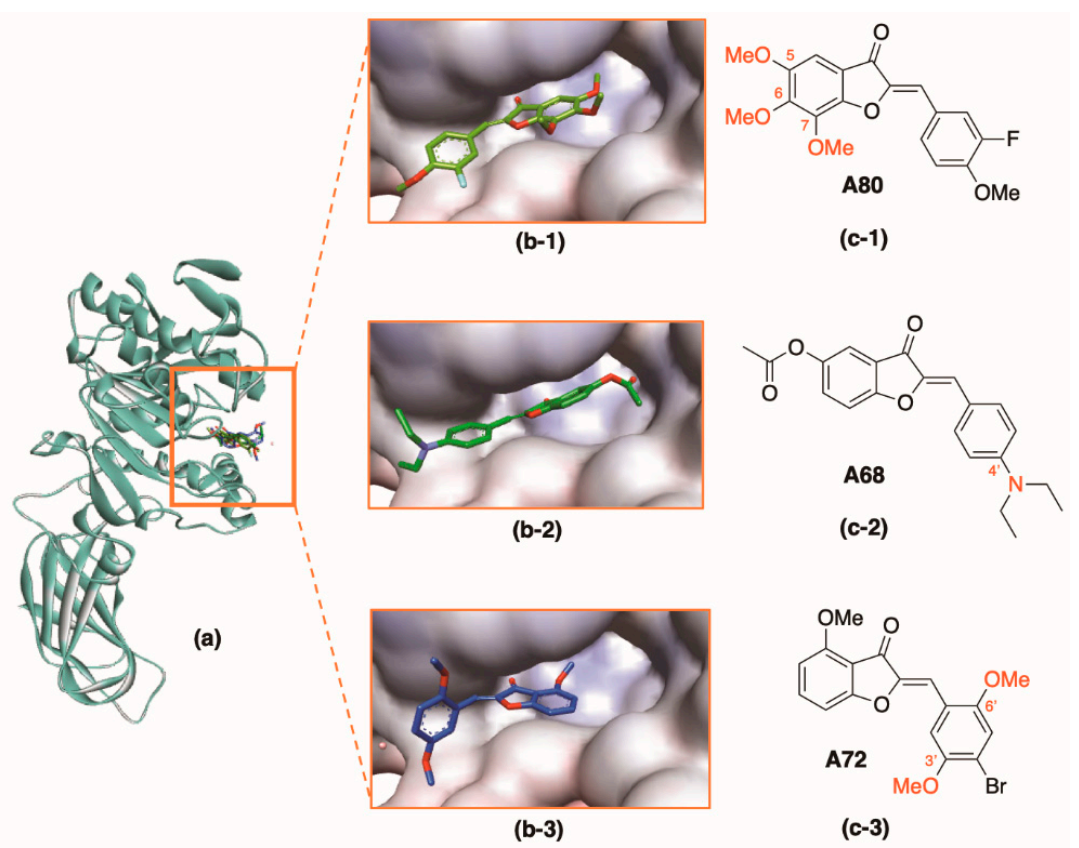

Figure 8. Some compounds of Group II in lipase (PDB ID: 1LPB) active site: (a) A80, A68, and A72 inside the active site in the ribbon style. (b) A80, A68, and A72 inside the active site. (c) 2D structures of A80, A68, and A72.

Overall, compounds (A9, A11, A14, A42, and A60) possess good docking scores and interact with the key residues of HPL (Figure 9). In terms of structures, they all have in common the oxygen-related substituents ( $\mathrm{OH}, \mathrm{OMe}$, and oxy-tether to the aromatic ring). The presence of the -OH group at ortho position on ring B (A11 and A9) much improves the binding affinity by forming additional hydrogen bonds with Ser152. Aurone A42 with 4,6-dihydroxy groups on ring A formed an intramolecular hydrogen bond enhancing its binding. A14 is an exceptional case. The bulky oxy-tether aromatic ring pushed the benzofuranone (rings A and C) out of the catalytic cavity, leaving ring B to interact with the catalytic trial Ser152-Asp176-His263 through hydrogen bonds. Interestingly, compound A14 still had the top docking score $\left(-10.6 \mathrm{kcal} \cdot \mathrm{mol}^{-1}\right)$. Moreover, A14 was reported as a leukemia-cell-resistance agent [49]. Therefore, A14 was selected for further study, to investigate the dynamics of the protein and ligand complex. 


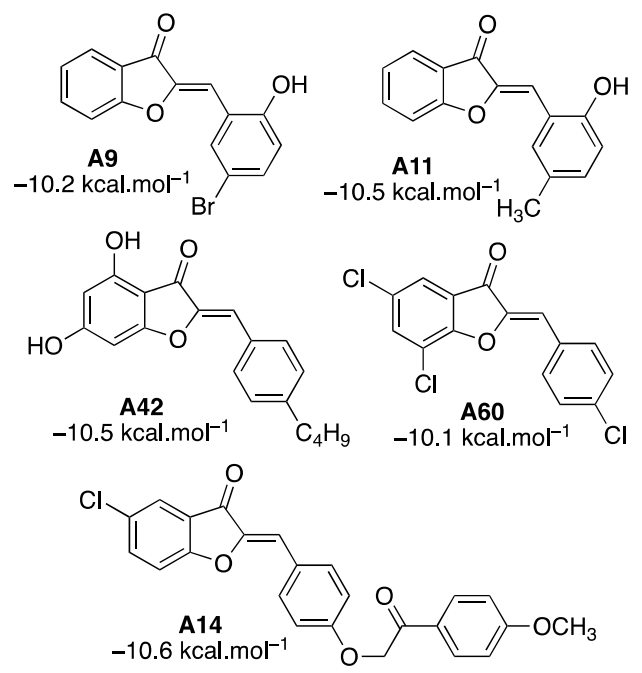

Figure 9. Compounds with the top docking scores and interacting with the key residues of human pancreatic lipase (HPL).

\subsection{Molecular Dynamics Simulations}

Protein-ligand docking provides only static interactions of protein and ligands, as protein was kept rigid and ligand was flexible. To better understand the stability and interactions of A14 and lipase under the conditions of the surrounding environment, the $50 \mathrm{~ns}$ molecular dynamics simulation of ligand A14-protein complex was performed by using GROMACS software [53]. Simulation of protein without ligand A14 (apo-protein) was also conducted under identical conditions, to compare with protein-ligand complex. The structural changes and dynamic behavior of protein-ligand complex were analyzed through RMSD (root mean square deviation), RMSF (root mean square fluctuation), Rg (radius of gyration), SASA (solvent accessibility surface area) values, and hydrogen-bond variations.

The stability of the 1LBP-A14 complex was investigated by comparing RMSD and RMSF values of the protein-ligand complex with the corresponding values of the initial apo-protein. RMSD measures the average change of atoms displacement for a protein-ligand complex compared to the initial apo-protein structure. RMSD values were calculated for all frames in the MD simulation trajectory. The 1LBP-A14 complex reached stability after $25 \mathrm{~ns}$ (RMSD values ranged from 2.5 to $4.0 \AA$ (or 0.25 to $0.40 \mathrm{~nm}$ )) while the apo-protein was relatively stable after $30 \mathrm{~ns}$. The RMSD value of ligand had an amplitude of oscillation about $1.5 \AA$ (from 0.5 to $2.0 \AA$ ), showing that the structure of ligand A14 was always stable during $50 \mathrm{~ns}$ simulation (Figure 10).

Another stability factor is the fluctuations of protein during simulation that were evaluated by analyzing RMSF values (Figure 11). RMSF values characterize changes in both the protein chain and the ligand atoms. RMSF values of all atoms of the ligand A14 were less than $2 \AA$. The oxygen atom of ligand A14 (O2), which created hydrogen bonds with Ser152 and His263 has the RMSF value of $1.2 \AA$, while atom O3 has the RMSF value of $0.6 \AA$. The data demonstrated that atoms O2 and O3 created stable bonds with protein. The fluctuations of Ser152, His263, and Phe77 residues during the interaction were all below $2.0 \AA$, which are perfectly acceptable (Figure 10). On RMSF values, amino acids of the apo-protein were more fluctuated than those of the ligand A14-protein complex. Residues of lipase active site interacting with ligand A14 were all stable with RMSF values below $2.0 \AA$ A especially, Ser152, His263, and Phe77 had RMSF values below $1.0 \AA$ A. It could be inferred that the interactions of protein and ligand made the structure of protein gaining more stability than the apo-protein and that ligand A14 fitted well in the active site and kept interacting with Ser152. 

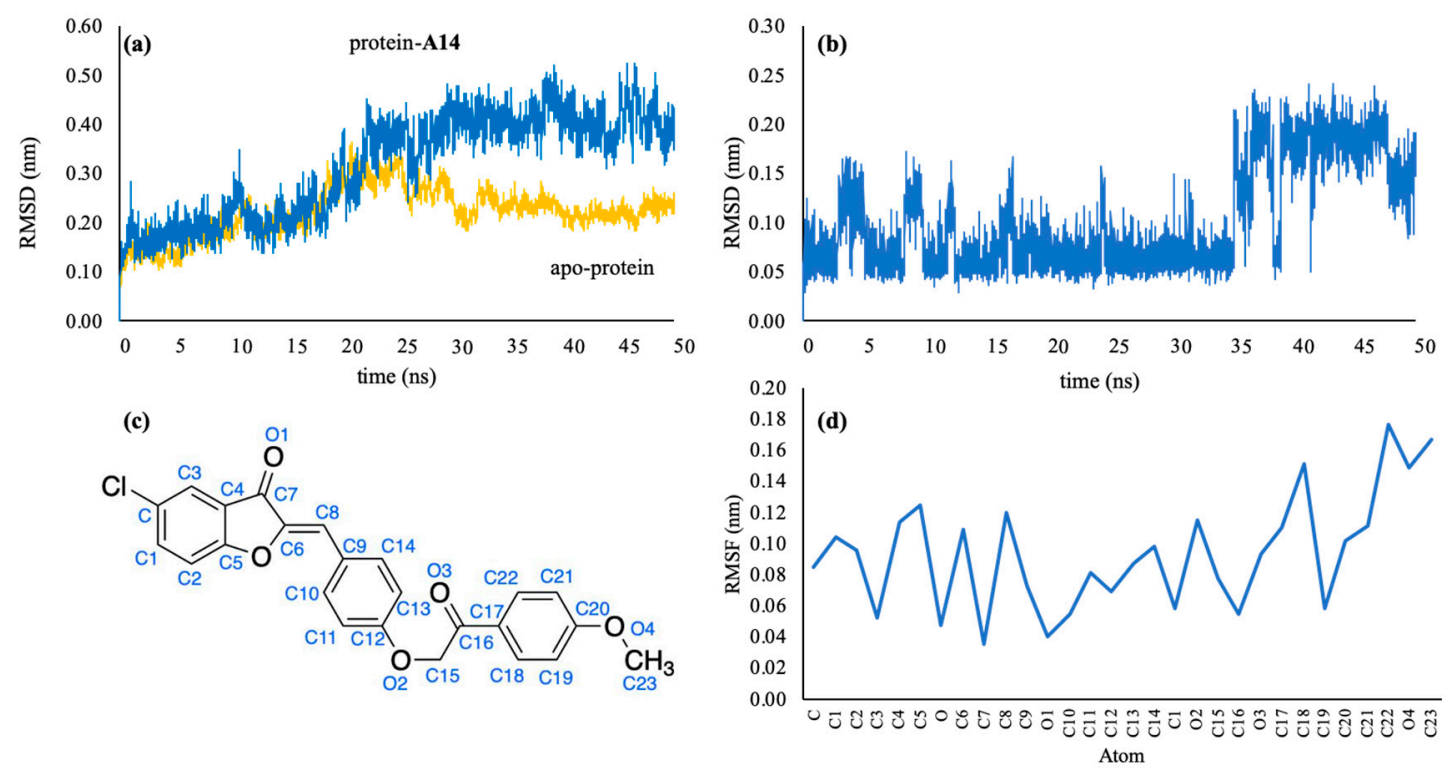

Figure 10. Stability of ligand A14 in protein-A14 during $50 \mathrm{~ns}$ molecular dynamics (MD) simulations. (a) Root mean square deviation (RMSD) values of 1LPB protein in apo-protein and protein-A14 complex; (b) RMSD values of ligand A14 in protein-A14 complex; (c) 2D structure of A14 with atomic numbering; and (d) Root mean square fluctuation (RMSF) heavy chain atoms of ligand A14.
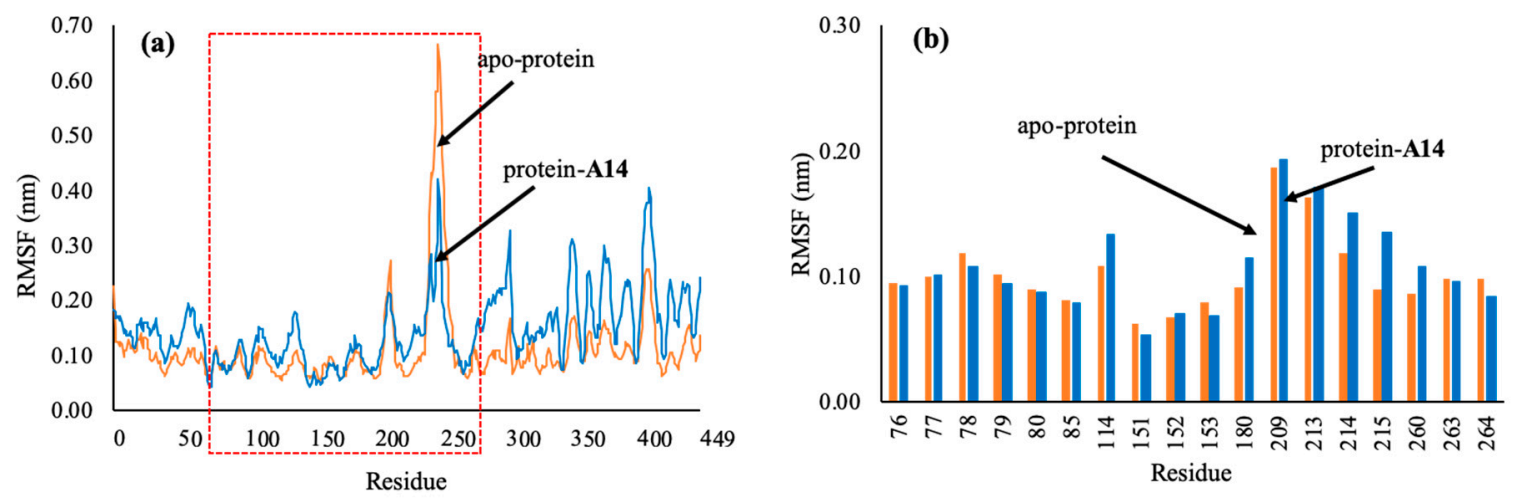

Figure 11. Root mean square fluctuation (RMSF) values of protein 1LPB during 50 ns MD simulations: (a) RMSF values of amino acids of protein 1LPB; (b) RMSF values of key residues in the active site of protein 1LPB. The protein-A14 complex and the apo-protein 1LBP were showed in blue and orange, respectively.

Moreover, the rigidity of the protein system after the MD simulation was examined via the Rg values. The data showed that Rg average values of protein in the 1LPB-A14 complex and of apo-protein were both about $2.6 \mathrm{~nm}$, meaning that protein retained a stable structure during the $\mathrm{MD}$ simulations (Figure 12). SASA values evaluate the ability of bimolecular surface area assessable to solvent molecules (Figure 13). After $1 \mathrm{~ns}$, SASA values of the protein in the complex and apo-protein reached the maximum values. The average values were 235 and $238 \mathrm{~nm}^{2}$, respectively. The lower SASA value of the protein in the ligand-protein complex denotes its relatively shrunken nature compared to the unbound structure. 

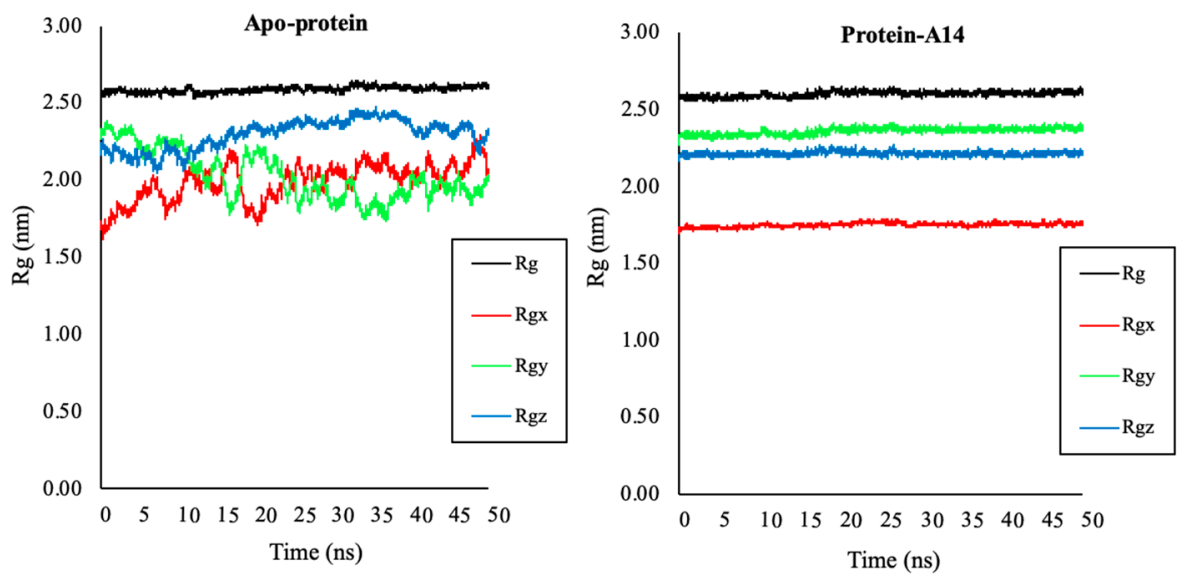

Figure 12. Radius of gyration ( $\mathrm{Rg}$ ) of protein $1 \mathrm{LPB}$ in apo-protein and protein-A14 complex during 50 ns MD simulations: (a) Rg of protein in the protein-A14 complex; (b) Rg of protein in the apo-protein. Total $\operatorname{Rg}$ of protein was in black, $\operatorname{Rgx}, \operatorname{Rgy}$, and $\operatorname{Rgz}$ around the $x-, y-$, and $z$-axis were in red, green, blue, respectively.

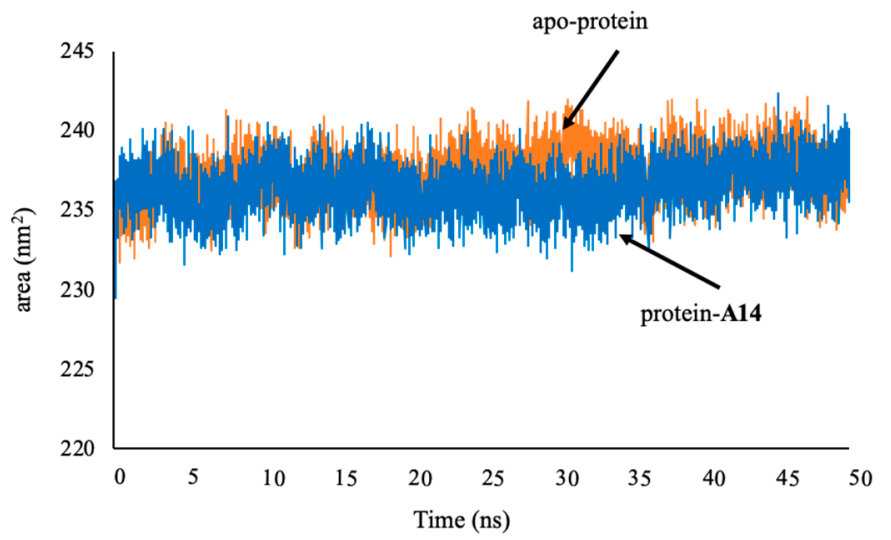

Figure 13. Total solvent-accessible surface area (SASA) of protein 1LPB in apo-protein and protein-A14 complex.

Protein and ligand interactions can be further monitored throughout the simulations. These interactions included hydrogen bonds, hydrophobic interactions, ionic interactions, and water bridges. Hydrogen bonds play a crucial role in ligand binding. The occupancies of hydrogen bonds between ligand A14 and protein 1LPB were determined by VMD software $\left(\mathrm{d} \leq 3.5 \AA\right.$ And $\left.\alpha \leq 120^{\circ}\right)$. Ligand A14 plays the role of both donor and acceptor in forming hydrogen bonds with the protein. A14 showed strong hydrogen bond interaction with the residue Phe77 (occupancy of 70.11\%) and moderate hydrogen bond interaction with Ser152 (occupancy of 56.74\%). Ligand A14 also interacted with residues His263, Ala259, Arg256, Pro180, Leu153, Ser152, His151, Phe115, Tyr114, Ile78, and Phe77, although these hydrogen bonds were weak (occupancies less than 10\%). The data proved that ligand A14 bound well and relative stably in the catalytic cavity of the HPL during the 50 ns MD simulation.

On the molecular docking and MD results, ligand A14 is a potential inhibitor as the ligand binding to the active site of protein 1LPB and mostly interacted with the key residues of the catalytic site (Ser152 and Phe77) by hydrogen bonds during the $50 \mathrm{~ns}$ MD simulation. The results of this study imply the potency of compound A14 for inhibiting HPL. 


\section{Materials and Methods}

\subsection{Preparation of Protein and Ligand for Docking}

Protein: The 3D structure of human pancreatic lipase was retrieved from the Protein Data Bank (PDB ID: 1LPB—resolution: $2.46 \AA$ ) (https://www.rcsb.org). The protein has a co-crystallized ligand-methoxy undecyl phosphonic acid. From the retrieved structure, protein chains binding with co-crystallized ligand was extracted, and then added polarized hydrogens by AutoDock Tools 1.5.7rc1 (Molecular Graphics Laboratory - The Scripps Research Institute, La Jolla, CA, USA).

Ligand: Ligands in this study were 82 aurone derivatives collected from reported publications investigating the biological effects of aurones [34-49]. These compounds were drawn in 2D by ISIS Draw 2.5 program and formatted in the MOL file. All 2D structures were converted to 3D structures whose energies were minimized with the YASARA Energy Minimization server (https: //www.yasara.org-YASARA Biosciences GmbH, Vienna, Austria).

\subsection{Molecular Docking}

The molecular docking process was implemented by AutoDock Vina software version 1.1.2, (Molecular Graphics Laboratory, The Scripps Research Institute, La Jolla, CA, USA) which combines knowledge-based potentials and empirical scoring [50]. The binding site parameters (x: 8,431 $\AA$; y: $24,417 \AA$; $z: 52,623 \AA)$ and the docking box dimensions $(18 \times 18 \times 18 \AA)$ were determined by redocking the co-crystallization ligand in the catalytic cavity. The results of molecular docking were evaluated through the criteria of binding structure, binding energy, and possible interactions between ligand and the key residues of the protein.

\subsection{Molecular Dynamics Simulations}

GROMACS 2018.01 software (Department of Biophysical Chemistry, University of Groningen, Groningen, The Netherlands) was used for the MD simulations of protein without ligand (apo-protein) and protein in complex with a ligand [53]. From the result of docking, choosing the best configuration of the best binding compound, and then adding hydrogen by Avogadro ver. 1.2.0n software (Avogadro development team, New York, NY, USA). The topology of the ligand structure was created by CGENFF with force field CHARMM27. The test system was put in a simulation box, and it was placed $1.0 \mathrm{~nm}$ from the box edge, which was a 12-surface polyhedron and contained the water solvent of the TIP3P model. $\mathrm{Na}^{+}, \mathrm{Cl}^{-}$ions were added to the system to balance the charge. The process of energy minimization took place to eliminate the negative interactions in the system. The system was balanced under the "isothermal-isobaric" conditions NVT ( $\mathrm{N}=$ number of particles, $\mathrm{V}=$ volume, and $\mathrm{T}=$ temperature $300 \mathrm{~K}$ ) and NPT ( $\mathrm{N}=$ number of particles, $\mathrm{P}=$ pressure 1 bar, and $\mathrm{T}=$ temperature $300 \mathrm{~K})$. Berendsen thermostat and Parrinello-Rahman barostat were used to maintain temperature and pressure. This equilibrium process lasted 1000 ps for each NVT and NPT system. The systems were simulated for $50 \mathrm{~ns}$, at a temperature of $300 \mathrm{~K}$, and pressure of 1 bar.

The result was recorded every $0.01 \mathrm{~ns}$ and evaluated through RMSD (root mean square deviation), RMSF, Rg, and SASA. Parameters were calculated by software GROMACS, VMD version 1.9.3 (Theoretical and Computational Biophysics Group, Beckman Institute for Advanced Science and Technology, University of Illinois at Urbana, IL, USA) [54,55], and represented as a chart by Microsoft Excel 2016 (Microsoft-COMDEX, Las Vegas, NV, USA).

\section{Conclusions}

Among 82 bioactive aurone derivatives, compound A14 ((Z)-5-chloro-2-(4-(2-(4-methoxyphenyl)2-oxoethoxy) benzylidene) benzofuran-3(2H)-one) stands out as a potential candidate for inhibiting human pancreatic lipase. A14 was docked into the HPL binding site with the highest docking score $\left(-10.6 \mathrm{kcal} \cdot \mathrm{mol}^{-1}\right)$. In $50 \mathrm{~ns}$ molecular dynamics simulations, A14 fitted well in the catalytic cavity of protein 1LPB and maintained the interactions by hydrogen bonds and hydrophobic interactions with 
the key residues of the catalytic site. Further studies on the synthesis of A14 and its derivatives, as well as in vitro lipase inhibitory assay are under investigation.

Supplementary Materials: The following are available online. Table S1. Docking results of 82 aurone compounds with protein.

Author Contributions: The authors have completed the work including P.T.V.N. for methodology and molecular docking validation, molecular dynamics simulation results, and editing and proofreading manuscript; H.A.H. for carrying out molecular docking, molecular dynamics simulations and preparing first manuscript draft; D.V.T. for checking the research data; T.-D.T. for results analysis, and C.-V.T.V. for molecular dynamics simulation results, and editing and proofreading manuscript. All authors have read and agreed to the published version of the manuscript.

Funding: The authors would like to thank the Vietnam National Foundation for Science and Technology Development (NAFOSTED) for financial support (Grant \# 108.05-2017.311) granted for Cam-Van T. Vo.

Conflicts of Interest: The authors declare no conflict of interest.

\section{References}

1. World Health Organization. Obesity and Overweight. 2018. Available online: http://www.who.int/newsroom/fact-sheets/detail/obesity-and-overweight (accessed on 21 August 2020).

2. Bell, J.A.; Kivimaki, M.; Hamer, M. Metabolically healthy obesity and risk of incident type 2 diabetes: A meta-analysis of prospective cohort studies. Obes. Rev. 2014, 15, 504-515. [CrossRef] [PubMed]

3. Abdullah, A.; Peeters, A.; De Courten, M.; Stoelwinder, J. The magnitude of association between overweight and obesity and the risk of diabetes: A meta-analysis of prospective cohort studies. Diabetes Res. Clin. Pract. 2010, 89, 309-319. [CrossRef] [PubMed]

4. Wilson, P.W.F.; D'Agostino, R.B.; Sullivan, L.; Parise, H.; Kannel, W.B. Overweight and Obesity as Determinants of Cardiovascular Risk. Arch. Intern. Med. 2002, 162, 1867-1872. [CrossRef] [PubMed]

5. Lu, Y.; Hajifathalian, K.; Ezzati, M.; Woodward, M.; Rimm, E.B.; Danaei, G.; Cefalù, A.; Averna, M.; Novo, S. Metabolic mediators of the effects of body-mass index, overweight, and obesity on coronary heart disease and stroke: A pooled analysis of 97 prospective cohorts with 1.8 million participants. Lancet 2014, 383, 970-983. [CrossRef] [PubMed]

6. Calle, E.E.; Thun, M.J. Obesity and cancer. Oncogene 2004, 23, 6365-6378. [CrossRef]

7. Daneschvar, H.L.; Aronson, M.D.; Smetana, G.W. FDA-Approved Anti-Obesity Drugs in the United States. Am. J. Med. 2016, 129, 879-e1-879-e6. [CrossRef]

8. Woodard, K.; Louque, L.; Hsia, D.S. Medications for the treatment of obesity in adolescents. Ther. Adv. Endocrinol. Metab. 2020, 11, 2042018820918789. [CrossRef]

9. Pilitsi, E.; Farr, O.M.; Polyzos, S.A.; Perakakis, N.; Nolen-Doerr, E.; Papathanasiou, A.-E.; Mantzoros, C.S. Pharmacotherapy of obesity: Available medications and drugs under investigation. Metabolism 2019, 92, 170-192. [CrossRef]

10. Winkler, F.K.; D'Arcy, A.; Hunziker, W. Structure of human pancreatic lipase. Nat. Cell Biol. 1990, 343, 771-774. [CrossRef]

11. Lowe, M.E. Structure and Function of Pancreatic Lipase and Colipase. Annu. Rev. Nutr. 1997, 17, 141-158. [CrossRef]

12. Egloff, M.-P.; Marguet, F.; Buono, G.; Verger, R.; Cambillau, C.; Van Tilbeurgh, H. The 2.46 .ANG. Resolution Structure of the Pancreatic Lipase-Colipase Complex Inhibited by a C11 Alkyl Phosphonate. Biochemistry 1995, 34, 2751-2762. [CrossRef] [PubMed]

13. Van Tilbeurgh, H.; Egloff, M.-P.; Martinez, C.; Rugani, N.; Verger, R.; Cambillau, C. Interfacial activation of the lipase-procolipase complex by mixed micelles revealed by X-ray crystallography. Nat. Cell Biol. 1993, 362, 814-820. [CrossRef] [PubMed]

14. Heck, A.M.; Yanovski, J.A.; Calis, K.A. Orlistat, a New Lipase Inhibitor for the Management of Obesity. Pharmacother. J. Hum. Pharmacol. Drug Ther. 2000, 20, 270-279. [CrossRef] [PubMed]

15. Hadváry, P.; Sidler, W.; Meister, W.; Vetter, W.; Wolfer, H. The lipase inhibitor tetrahydrolipstatin binds covalently to the putative active site serine of pancreatic lipase. J. Boil. Chem. 1991, 266, 2021-2027.

16. Lunagariya, N.A.; Patel, N.K.; Jagtap, S.C.; Bhutani, K.K. Inhibitors of pancreatic lipase: State of the art and clinical perspectives. EXCLI J. 2014, 13, 897-921. 
17. Birari, R.B.; Bhutani, K.K. Pancreatic lipase inhibitors from natural sources: Unexplored potential. Drug Discov. Today 2007, 12, 879-889. [CrossRef]

18. Kumar, P.; Dubey, K.K. Current trends and future prospects of lipstatin: A lipase inhibitor and pro-drug for obesity. RSC Adv. 2015, 5, 86954-86966. [CrossRef]

19. Emimmal, M.E.S.; Sankar, V.; Se, M.E. Synthesis and Pancreatic Lipase Inhibitory Activity of Phenacyl Esters of N-Aroyl Amino Acids. Curr. Enzym. Inhib. 2019, 15, 133-143. [CrossRef]

20. Sridhar, S.; Ginson, G.; Reddy, P.V.; Tantak, M.P.; Kumar, D.; Paul, A.T. Synthesis, evaluation and molecular modelling studies of 2-(carbazol-3-yl)-2-oxoacetamide analogues as a new class of potential pancreatic lipase inhibitors. Bioorg. Med. Chem. 2017, 25, 609-620. [CrossRef]

21. Sridhar, S.N.C.; Bhurta, D.; Kantiwal, D.; George, G.; Monga, V.; Paul, A.T. Design, synthesis, biological evaluation and molecular modelling studies of novel diaryl substituted pyrazolyl thiazolidinediones as potent pancreatic lipase inhibitors. Bioorg. Med. Chem. Lett. 2017, 27, 3749-3754. [CrossRef]

22. Chauhan, D.; George, G.; Sridhar, S.N.C.; Bhatia, R.; Paul, A.T.; Monga, V. Design, synthesis, biological evaluation, and molecular modeling studies of rhodanine derivatives as pancreatic lipase inhibitors. Arch. Der Pharm. 2019, 352, e1900029. [CrossRef] [PubMed]

23. Li, Y.-F.; Chang, Y.-Q.; Deng, J.; Li, W.-X.; Jian, J.; Gao, J.-S.; Wan, X.; Gao, H.; Kurihara, H.; Sun, P.-H.; et al. Prediction and evaluation of the lipase inhibitory activities of tea polyphenols with 3D-QSAR models. Sci. Rep. 2016, 6, 34387. [CrossRef] [PubMed]

24. Ahmed, B.; Ali Ashfaq, U.; Mirza, M.U. Medicinal plant phytochemicals and their inhibitory activities against pancreatic lipase: Molecular docking combined with molecular dynamics simulation approach. Nat. Prod. Res. 2017, 32, 1123-1129. [CrossRef] [PubMed]

25. Kalathiya, U.; Padariya, M.; Baginski, M. Identification of $1 \mathrm{H}$-indene-(1,3,5,6)-tetrol derivatives as potent pancreatic lipase inhibitors using molecular docking and molecular dynamics approach. Biotechnol. Appl. Biochem. 2015, 63, 765-778. [CrossRef] [PubMed]

26. Panwar, U.; Singh, S.K. Identification of Novel Pancreatic Lipase Inhibitors Using In Silico Studies. Endocr. Metab. Immune Disord. Drug Targets 2019, 19, 449-457. [CrossRef]

27. Won, S.-R.; Kim, S.-K.; Kim, Y.-M.; Lee, P.-H.; Ryu, J.-H.; Kim, J.-W.; Rhee, H.-I. Licochalcone A: A lipase inhibitor from the roots of Glycyrrhiza uralensis. Food Res. Int. 2007, 40, 1046-1050. [CrossRef]

28. Kumar, S.; Alagawadi, K.R. Anti-obesity effects of galangin, a pancreatic lipase inhibitor in cafeteria diet fed female rats. Pharm. Biol. 2013, 51, 607-613. [CrossRef]

29. Kawaguchi, K.; Mizuno, T.; Aida, K.; Uchino, K. Hesperidin as an Inhibitor of Lipases from Porcine Pancreas and Pseudomonas. Biosci. Biotechnol. Biochem. 1997, 61, 102-104. [CrossRef]

30. Hou, X.-D.; Ge, G.-B.; Weng, Z.-M.; Dai, Z.-R.; Leng, Y.-H.; Ding, L.-L.; Jin, L.-L.; Yu, Y.; Cao, Y.-F.; Hou, J. Natural constituents from Cortex Mori Radicis as new pancreatic lipase inhibitors. Bioorg. Chem. 2018, 80, 577-584. [CrossRef]

31. Ninomiya, M.; Koketsu, M. Minor Flavonoids (Chalcones, Flavanones, Dihydrochalcones, and Aurones). In Natural Products; Springer Science and Business Media LLC: Berlin, Germany, 2013; pp. 1867-1900.

32. Roussaki, M.; Lima, S.C.; Kypreou, A.-M.; Kefalas, P.; Cordeiro da Silva, A.; Detsi, A. Aurones: A Promising Heterocyclic Scaffold for the Development of Potent Antileishmanial Agents. Int. J. Med. Chem. 2012, 2012, 196921. [CrossRef]

33. Boumendjel, A. [General Articles] Aurones: A Subclass of Flavones with Promising Biological Potential. Curr. Med. Chem. 2003, 10, 2621-2630. [CrossRef] [PubMed]

34. Hassan, G.S.; Georgey, H.H.; George, R.F.; Mohamed, E.R. Aurones and furoaurones: Biological activities and synthesis. Bull. Fac. Pharm. Cairo Univ. 2018, 56, 121-127. [CrossRef]

35. Hassan, G.S.; Abou-Seri, S.M.; Kamel, G.; Ali, M.M. Celecoxib analogs bearing benzofuran moiety as cyclooxygenase-2 inhibitors: Design, synthesis and evaluation as potential anti-inflammatory agents. Eur. J. Med. Chem. 2014, 76, 482-493. [CrossRef] [PubMed]

36. Jardosh, H.H.; Patel, M.P. Antimicrobial and antioxidant evaluation of new quinolone based aurone analogs. Arab. J. Chem. 2017, 10, S3781-S3791. [CrossRef]

37. Carrasco, M.P.; Newton, A.S.; Gonçalves, L.M.; Góis, A.; Machado, M.; Gut, J.; Nogueira, F.; Hänscheid, T.; Guedes, R.C.; Dos Santos, D.J.V.A.; et al. Probing the aurone scaffold against Plasmodium falciparum: Design, synthesis and antimalarial activity. Eur. J. Med. Chem. 2014, 80, 523-534. [CrossRef] 
38. Souard, F.; Okombi, S.; Beney, C.; Chevalley, S.; Valentin, A.; Boumendjel, A. 1-Azaaurones derived from the naturally occurring aurones as potential antimalarial drugs. Bioorg. Med. Chem. 2010, 18, 5724-5731. [CrossRef]

39. Meguellati, A.; Ahmed-Belkacem, A.; Yi, W.; Haudecoeur, R.; Crouillère, M.; Brillet, R.; Pawlotsky, J.-M.; Boumendjel, A.; Peuchmaur, M. B-ring modified aurones as promising allosteric inhibitors of hepatitis C virus RNA-dependent RNA polymerase. Eur. J. Med. Chem. 2014, 80, 579-592. [CrossRef]

40. Haudecoeur, R.; Ahmed-Belkacem, A.; Yi, W.; Fortuné, A.; Brillet, R.; Belle, C.; Nicolle, E.; Pallier, C.; Pawlotsky, J.-M.; Boumendjel, A. Discovery of Naturally Occurring Aurones That Are Potent Allosteric Inhibitors of Hepatitis C Virus RNA-Dependent RNA Polymerase. J. Med. Chem. 2011, 54, 5395-5402. [CrossRef]

41. Detsi, A.; Majdalani, M.; Kontogiorgis, C.A.; Hadjipavlou-Litina, D.; Kefalas, P. Natural and synthetic 2'-hydroxy-chalcones and aurones: Synthesis, characterization and evaluation of the antioxidant and soybean lipoxygenase inhibitory activity. Bioorg. Med. Chem. 2009, 17, 8073-8085. [CrossRef]

42. Narsinghani, T.; Sharma, P.; Bhargav, S. Synthesis, docking studies and antioxidant activity of some chalcone and aurone derivatives. Med. Chem. Res. 2012, 22, 4059-4068. [CrossRef]

43. Huong, T.T.; Cuong, N.X.; Tram, L.H.; Quang, T.T.; Van Duong, L.; Nam, N.H.; Nguyen, T.D.; Huong, P.T.T.; Diep, C.N.; Van Kiem, P.; et al. A new prenylated aurone fromArtocarpus altilis. J. Asian Nat. Prod. Res. 2012, 14, 923-928. [CrossRef] [PubMed]

44. Molitor, C.; Mauracher, S.G.; Pargan, S.; Mayer, R.L.; Halbwirth, H.; Rompel, A. Latent and active aurone synthase from petals of C. grandiflora: A polyphenol oxidase with unique characteristics. Planta 2015, 242, 519-537. [CrossRef] [PubMed]

45. Elhadi, A.A.; Osman, H.; Iqbal, M.A.; Rajeswari, S.K.; Ahamed, M.B.K.; Majid, A.M.S.A.; Rosli, M.M.; Razak, I.A.; Majid, A.S.A. Synthesis and structural elucidation of two new series of aurone derivatives as potent inhibitors against the proliferation of human cancer cells. Med. Chem. Res. 2015, 24, 3504-3515. [CrossRef]

46. Hassan, G.S.; Georgey, H.H.; George, R.F.; Mohammed, E.R. Construction of some cytotoxic agents with aurone and furoaurone scaffolds. Futur. Med. Chem. 2018, 10, 27-52. [CrossRef]

47. Lawrence, N.J.; Rennison, D.; McGown, A.T.; Hadfield, J.A. The total synthesis of an aurone isolated from Uvaria hamiltonii: Aurones and flavones as anticancer agents. Bioorg. Med. Chem. Lett. 2003, 13, 3759-3763. [CrossRef]

48. Uesawa, Y.; Sakagami, H.; Ikezoe, N.; Takao, K.; Kagaya, H.; Sugita, Y. Quantitative Structure-Cytotoxicity Relationship of Aurones. Anticancer. Res. 2017, 37, 6169-6176. [CrossRef]

49. Demirayak, S.; Yurttas, L.; Karaburun, N.G.; Karaburun, A.Ç.; Kayagil, I. Synthesis and anti-cancer activity evaluation of new aurone derivatives. J. Enzym. Inhib. Med. Chem. 2015, 30, 816-825. [CrossRef]

50. Trott, O.; Olson, A. AutoDock Vina: Improving the speed and accuracy of docking with a new scoring function, efficient optimization, and multithreading. J. Comput. Chem. 2009, 31, 455-461. [CrossRef]

51. Lüthi-Peng, Q.; Märki, H.P.; Hadváry, P. Identification of the active-site serine in human pancreatic lipase by chemical modification with tetrahydrolipstatin. FEBS Lett. 1992, 299, 111-115. [CrossRef]

52. Cygler, M.; Schrag, J.D.; Ergan, F. Advances in Structural Understanding of Lipases. Biotechnol. Genet. Eng. Rev. 1992, 10, 143-184. [CrossRef]

53. Abraham, M.; Van Der Spoel, D.; Lindahl, E.; Hess, B. the GROMACS development team. GROMACS User Man. Version 2014, 5, 1-298.

54. Kirchmair, J.; Markt, P.; Distinto, S.; Wolber, G.; Langer, T. Evaluation of the performance of 3D virtual screening protocols: RMSD comparisons, enrichment assessments, and decoy selection-What can we learn from earlier mistakes? J. Comput. Mol. Des. 2008, 22, 213-228. [CrossRef] [PubMed]

55. Humphrey, W.; Dalke, A.; Schulten, K. VMD: Visual molecular dynamics. J. Mol. Graph. 1996, 14, 33-38. [CrossRef]

(C) 2020 by the authors. Licensee MDPI, Basel, Switzerland. This article is an open access article distributed under the terms and conditions of the Creative Commons Attribution (CC BY) license (http://creativecommons.org/licenses/by/4.0/). 